\title{
O ENSINO DE HISTÓRIA NO PARANÁ, NA DÉCADA DE SETENTA: AS LEGISLAÇÕES E O PIONEIRISMO DO ESTADO NAS REFORMAS EDUCACIONAIS
}

Cláudia Regina Kawka Martins ${ }^{1}$

RESUMO:

Este artigo busca apresentar alguns dos resultados da pesquisa ${ }^{2}$ realizada sobre o ensino de História no Paraná, na década de setenta. O objetivo foi o de analisar como a reforma de ensino de 1971, conhecida como a Lei $\mathrm{n}^{\circ} 5692$, atingiu o ensino de História paranaense. O problema investigado foi a especificidade na implantação da reforma no Paraná e principalmente a situação do ensino de História da $5^{\mathrm{a}}$ à $8^{\mathrm{a}}$ série do período.

PALAVRAS-CHAVE:

ensino de História, reforma de ensino, legislação educacional.

\section{Introdução}

O currículo de Estudos Sociais, publicado no Paraná em 1976, foi elaborado tendo em vista os objetivos da Lei 5692/71. Ele é produto e reflexo do que se queria para a educação naquele período, do tipo de cidadão que o Estado - governado pelos militares - pretendia formar, sempre voltado para os interesses econômicos desenvolvimentistas.

${ }^{1}$ Professora de História do Colégio Militar de Curitiba e de História da Educação do Centro Universitário Campos de Andrade - Uniandrade, Curitiba.

${ }^{2}$ Este artigo é parte da dissertação de Mestrado intitulada $O$ Ensino de História no Paraná, na década de setenta: legislações e práticas, defendida em dezembro de 1999 no Curso de Pós-graduação em Educação, Setor de Educação, da Universidade Federal do Paraná, sob orientação da professora doutora Serlei Maria Fischer Ranzi. 
Assim suas concepções teóricas, metodológicas e conteúdos refletem a época em que foi escrito. As reformas de ensino do período, a Lei 5540/68 e a 5692/71, respectivamente chamadas de Reforma Universitária e Reforma do ensino do $1^{\circ}$ e $2^{\circ}$ graus, foram realizadas tendo em vista as necessidades do período. $O$ ensino, principalmente o do $2^{\circ}$ grau, teve o objetivo de formar alunos aptos para o mercado de trabalho para atender uma demanda, a qual estava muito ligada às empresas de capital estrangeiro.

Com a Lei 5692/71, determinou-se, no seu Artigo $4^{\circ}$, que os currículos de ensino do $1^{\circ}$ e $2^{\circ}$ graus teriam um núcleo comum obrigatório em âmbito nacional e uma parte diversificada para atender às peculiaridades locais e que caberia ao Conselho Federal de Educação fixar as matérias relativas ao Núcleo Comum. Assim, pela Resolução no 08/71, anexada ao Parecer 853/71 do Conselho Federal de Educação, no seu Artigo 1, os conteúdos escolares foram divididos em três áreas do conhecimento: Estudos Sociais, Comunicação e Expressão e Iniciação às Ciências. Pretendia-se fazer um estudo integrado de disciplinas próximas, e os Estudos Sociais, segundo o Parecer, seriam o eixo ou o centro do currículo.

O objetivo dos Estudos Sociais, segundo a Resolução $\mathrm{n}^{\mathrm{O}}$ 08/71, no seu Artigo 3, era o "ajustamento crescente do educando ao meio, cada vez mais amplo e complexo, em que deve não apenas viver como conviver, sem deixar de atribuir a devida ênfase ao conhecimento do Brasil na perspectiva atual do seu desenvolvimento." (PARANÁ. Resolução no 08/71, 1971, p. 16). 


\section{O ensino de História no Paraná, nos anos setenta: as legislações}

Após a publicação da Lei 5692/71, o governo do Estado, através da Fundação Educacional do Paraná (FUNDEPAR), iniciou uma série de publicações relativas à reforma do ensino, com o intuito de divulgá-la entre os professores. No primeiro fascículo publicado, intitulado Ensino de $1^{\circ}$ e $2^{\circ}$ graus, consta um texto escrito pelo Secretário da Educação e Cultura do período, Roberto Linhares da Costa. Seguem-se alguns trechos:

Reputo oportuno e imprescindível trazer aos professores, educadores e técnicos - que são, afinal, os executores da educação - o conhecimento da lei e das providências decorrentes dela, que visam à nova metodologia do ensino: os fundamentos teóricos da reforma; as inovações da lei, seu significado para o desenvolvimento brasileiro, que é seu derradeiro e grande objetivo. Não se entende, evidentemente, desenvolvimento sem educação, pois que a educação é o pressuposto e lídimo fundamento do progresso econômico, social, tecnológico e científico. Por isso, os novos sistemas preconizam preparar o homem para as responsabilidades do cotidiano real, com educação geral e humanística no $1^{\circ}$ grau e técnica profissionalizante no $2^{\circ} \mathrm{grau}$, a fim de que o estudante brasileiro, mesmo sem alcançar a Universidade, possa desde logo afirmar-se como elemento produtivo dentro da comunidade, tão respeitado quanto útil no seio da família e da sociedade. [...] (PARANÁ. Ensino de $1^{\circ}$ e $2^{\circ}$ graus, 1971, p. 2).

O governo do Paraná, no mesmo ano da aprovação da Lei 5692, apresentou um plano de implantação da reforma bastante detalhado, o qual tinha por objetivo colocar o Estado numa posição de destaque no que diz respeito a sua implantação.

Apenas três meses após a publicação da Lei 5692/71, o governo do Paraná, através da Secretaria da Educação e Cultura, 
publicou o Documento-base para o planejamento prévio para implantação do sistema de ensino do $1^{\circ}$ e $2^{\circ}$ graus, com dois volumes e 495 páginas. A rapidez na sua publicação indica mais uma vez a preocupação do governo do Estado em estar na vanguarda das reformas do ensino. Segundo esse documento, seu objetivo era "expor a situação do ensino paranaense e sugerir diretrizes e objetivos para o planejamento do sistema educacional do Estado." (PARANÁ. Documento base..., 1971, p. 2).

Assim expressava-se o Secretário da Educação e Cultura do período, Haroldo Souto Carvalhinho, na apresentação do referido documento:

Este planejamento prévio é uma primeira tomada de posição diante da problemática nova colocada pela lei da reforma do ensino; e nesta linha, procura afirmar a administração estadual o alcance de uma verdadeira revolução educacional em nosso país [...] o que significa fazer da escola um agente dinâmico e eficaz na formação dos recursos humanos necessários ao progresso do país. Assim, conscientes da preeminência da função social da educação no processo de desenvolvimento e na criação de um país pleno de possibilidades e pujança, a Secretaria da Educação e Cultura, o Conselho Estadual de Educação e a Fundação Educacional do Estado do Paraná, irmanados com as universidades e com a iniciativa particular, procuram, apoiados em critérios de racionalidade e espírito de cooperação e integração, dar os primeiros passos na atualização e modernização educacionais do Paraná, com os olhos voltados para a construção do Brasil futuro. (PARANÁ. Documento base..., 1971, p. 2).

No documento há um parecer bastante favorável à reforma, pois ela apresentaria "um cunho descentralizador [...] fazendo com que os Estados sejam responsáveis pela educação que administram, permitindo-lhes participar, criar e renovar constantemente sua estrutura, de tal modo que não se restringiria 
apenas a uma reforma, mas sim a uma atualização constante e contínua." (PARANÁ. Documento base..., 1971, p. 19).

A reforma deveria assim ser vista como um instrumento que viabilizaria o alcance de objetivos mais amplos, como "a elevação da escolaridade média da população, a melhoria dos padrões educativos dos sistemas escolares e o equilíbrio entre a produção educacional e os requerimentos de recursos humanos do processo de desenvolvimento." (PARANÁ. Documento base..., 1971, p. 19).

No Paraná, os objetivos gerais da reforma estadual do ensino seriam oferecer iguais oportunidades educacionais a todos, tendo em vista sempre o desenvolvimento econômico. Afirmava-se no Documento-base para o planejamento prévio para implantação do sistema de ensino de $1^{\circ}$ e $2^{\circ}$ graus que era de suma importância elevar a qualidade do ensino a fim de que não se continuassem a perder recursos com a elevada repetência e com os baixos níveis de desenvolvimento e conhecimentos oferecidos até então.

Para que se atingissem esses objetivos, o documento trazia as "medidas de urgência" que deveriam ser tomadas, tais como a reestruturação dos currículos de acordo com a nova lei e a organização de equipes, em nível regional e municipal, para o estudo dos currículos.

Em seguida, o documento passa a tratar da maneira como seria realizada a implantação da reforma no Paraná. A implantação da Lei 5692/71 deveria ser feita de forma progressiva nos Estados, de acordo com suas possibilidades e legislação de ensino.

Para a introdução da reforma de ensino no Estado do Paraná, o documento apresenta de forma bastante detalhada todas as etapas necessárias para a sua execução e expansão.

Em 1972, seria realizada a "implantação-piloto", a qual 
abrangeria a capital, Curitiba, que receberia um projeto especial, a ser detalhado adiante, e mais oito grandes cidades do Estado: Paranaguá, Ponta Grossa, Jacarezinho, Londrina, Maringá, Campo Mourão, Guarapuava e União da Vitória. Essas cidades representavam na época $44,5 \%$ da população total das cidades paranaenses. Portanto, já nesse ano, praticamente metade do Estado estaria sendo atingido.

Em seguida, começariam as etapas de expansão da reforma para o restante do Estado. Assim, em 1973, na primeira etapa de expansão, mais 37 cidades seriam atingidas pela reforma. Essas cidades seriam aquelas com população superior a dez mil habitantes e ainda cinco outras com população entre cinco mil e dez mil habitantes. Em seguida, viria a etapa que atingiria mais trinta cidades com população superior a cinco mil habitantes e inferior a dez mil. A partir de 1975, começaria a terceira etapa da expansão, onde seriam atingidas as cidades com população entre dois e cinco mil habitantes, que somavam oitenta e sete cidades. Finalmente, em 1976, ocorreria a quarta e última etapa, a qual atingiria as cento e vinte e cinco cidades restantes, com população inferior a dois mil habitantes.

\section{O Estado do Paraná e o pioneirismo nas reformas educacionais}

A idéia do pioneirismo do Paraná nas reformas educacionais é algo que aparece nos discursos dos governadores e Secretários de Educação desde 1964. Logo após a Revolução de 1964, foi criado no Paraná o Conselho Estadual de Educação, através da Lei 4978 de 05 de dezembro de 1964.

O governador do Estado desse período era Ney Braga e, segundo essa lei, "inaugurava-se nova fase na história educacional do Paraná." O artigo $1^{\circ}$ da Lei 4978/64 falava dos 
fins da educação no Paraná, onde destacava-se o seguinte: "o oferecimento, a todos os habitantes do Estado, de idênticas oportunidades educacionais, a fim de habilitá-los a participar efetivamente do seu desenvolvimento social e econômico" e "a pesquisa de vocação, o desenvolvimento de aptidóes e a oportunidade de orientação profissional, tendo em vista a perfeita e harmônica integração do educando na comunidade de trabalho." (PARANÁ. Lei no 4978/64, 1965, p. 10).

A idéia de ligação ente educação e desenvolvimento já aparece nos discursos do governador Ney Braga no início dos anos sessenta. "Assim, visando superar os problemas não resolvidos pela gestão anterior, Ney Braga cria a 'Lei Estadual de Diretrizes e Bases da Educação' e o 'Plano Estadual de Educação' (1962), ambos com o objetivo de organizar um sistema de ensino ajustado às [...] necessidades quantitativas e qualitativas do nosso desenvolvimento." (IPARDES, 1989, p. 59).

Nota-se que muitos desses fins, tais como a participação no desenvolvimento econômico do país e a orientação profissional, aparecem mais tarde nos objetivos da Lei 5692/71, que seria publicada seis anos depois. Essa ligação da educação com o desenvolvimento fazia parte dos discursos da época e estava embasada nas teorias do "capital humano".

Segundo Mariana ALMEIDA (1993, p. 166-167), essa teoria foi desenvolvida nesse período principalmente pelos economistas ingleses e americanos e seu pressuposto básico "firmava-se na compreensão da educação e do treinamento como responsáveis pelo crescimento da produtividade. Desta forma, a educação recebeu como função primordial o propósito de desenvolver habilidades e conhecimentos, visando ao aumento do grau de produtividade." Com esse objetivo, foram criados vários acordos de financiamento entre o MEC e a USAID (Agência Norte-Americana para o Desenvolvimento 
Internacional). O Paraná, alguns anos depois, recebeu uma ajuda financeira por parte desses acordos para levar adiante sua reforma educacional.

Ainda segundo essa mesma autora,

A influência dos EUA no processo de desenvolvimento nacional, tendo como uma de suas diretrizes a educação, continuou se fazendo sentir em relação ao preparo do "capital humano", voltado agora, acima de tudo, para o lucro e suas implicações no mercado interno. Assim, no âmbito da teoria do capital humano, a educação é tomada como um "investimento capaz de produzir renda". Se de um lado ressalta as vantagens da individualidade e seduz com possibilidades de ascensão social, de fato, de outro lado tem em mira uma ascensão voltada mais para as exigências do consumo supérfluo. (1993, p. 167-168).

Percebe-se, então, que a ajuda financeira externa voltada para a melhoria educacional tinha por objetivo aumentar o mercado consumidor para os produtos estrangeiros. É o interesse econômico que estava acima de tudo.

Alguns anos depois, em 1969, foi criado no Estado o I SENPAR - Simpósio de Ensino do Paraná - através do Decreto $\mathrm{n}^{\circ} 17145$ daquele ano. Esse Simpósio foi realizado em Curitiba de 13 a 20 de dezembro de 1969 e reuniu inúmeros participantes, dentre os quais estavam professores, diretores, inspetores de ensino, prefeitos, vereadores, autoridades civis, militares e eclesiásticas de vários municípios do Estado e autoridades de fora do Paraná, tais como o Presidente do Conselho Federal de Educação. (PARANÁ. I SENPAR Recomendações finais, 1969 , p. 1).

Os objetivos desse Simpósio eram, segundo essa mesma fonte, "discutir os resultados obtidos nas atividades educacionais desenvolvidas, conscientizar professores para as 
reformulações do ensino que se fizerem necessárias e recomendar as medidas para a sua implantação." (PARANÁ. I SENPAR - Recomendações Finais, 1969, p. 1). Então já no final da década de sessenta o Estado do Paraná estava preocupado em fazer suas reformulações no sistema educacional.

Segundo palavras do governador da época, Ney Braga, no discurso de abertura do Simpósio, o objetivo era "colocar o Estado na vanguarda do panorama educacional". Nesse Simpósio nasceu o Plano Estadual de Ensino, o qual criou a Reforma de Ensino no Paraná, onde ficou decidido que seria criado um sistema de Ensino Fundamental que substituiria os níveis primário e ginasial. Assim o ensino básico ficaria unificado "para que se possa atender a população de 7 a 14 anos em processo contínuo, abolindo-se conseqüentemente o tradicional Exame de Admissão" (PARANÁ. I SENPAR Recomendações Finais, 1969, p. 6).

O Ensino Fundamental seria inicialmente implantado nas escolas das cidades que eram sedes das cinqüenta e cinco Inspetorias Regionais de Ensino - criadas pela Lei n. 4460 de 06 de novembro de 1961 - as quais seriam consideradas áreaspiloto e núcleos de expansão para o restante das escolas do Estado. Nesse Simpósio também decidiu-se que "as habilidades manuais e técnicas ofereçam ao educando uma riqueza de oportunidades e experiências variadas que propiciem uma sondagem vocacional e o habilitem a uma melhor escolha profissional futura." (PARANÁ. I SENPAR - Recomendações Finais, 1969, p. 7).

Conclui-se, portanto, que muito daquilo que foi publicado pela Lei 5692/71 já estava sendo aplicado no Paraná anos antes, como é o caso do Ensino Fundamental substituindo o primário e o ginásio e o fim do exame de admissão para a $5^{\text {a }}$ série. A única coisa que mudou com a nova lei foi o nome, pois 
em 1971 essa unificação do ensino básico passou a chamar-se Ensino do $1^{\circ}$ grau, e não Educação Fundamental. A questão do ensino profissionalizante também já estava presente nas propostas da reforma da época. É a "vanguarda" do Estado do Paraná, de que o governador falava no seu discurso, citado anteriormente.

A seguir segue-se um trecho do discurso do governador Ney Braga, durante a instalação do I SENPAR, no qual percebe-se claramente a ligação da educação com o desenvolvimento econômico:

O Plano Estadual de Educação não será o primeiro a ser elaborado no Brasil. Mas, com a ajuda de todos os que aqui estão, poderá ser o mais moderno e o mais lucidamente estruturado. Essa lucidez virá, tenho certeza, como conseqüência do diálogo amplo e democrático que aqui vai se desenrolar. Todos já têm a consciência de participarem de uma verdadeira revolução educacional, nesta hora em que o desenvolvimento do Paraná reclama um tipo de escola capaz de atuar como fator de aceleração do próprio desenvolvimento. [...] Neste governo, foi desfraldada a bandeira do desenvolvimento integrado, encaminhou-se a luta consciente para humanizar o progresso. No setor da educação essa filosofia vai se traduzir agora num plano delineado com objetividade e inteligência. Um plano que realize o ideal da escola humana e ao mesmo tempo geratriz de gente capacitada para as novas tarefas do desenvolvimento. Esse é o plano que todo o Paraná vai elaborar aqui, assinalando um novo marco na história da educação, e abrindo um novo caminho para o futuro. (PARANÁ. Discursos proferidos na Sessão Solene de Abertura do I SENPAR, 1969, p. 2). [sem grifo no original].

Em julho de 1970, foi realizado no Paraná o III Encontro Regional sobre Planejamento da Educação (ERPLED). Ali reuniram-se representantes dos três Estados da região Sul com o objetivo de prosseguir e encerrar o ciclo dos ERPLEDES, os 
quais se desenrolaram em Porto Alegre, em 1968, e em Florianópolis, em 1969. Os temas discutidos nesse encontro foram a implementação dos Planos Estaduais de Educação, o diagnóstico dos recursos humanos e as estatísticas sobre o planejamento educacional. No relatório desse encontro, destaca-se o pronunciamento do professor Osvaldo Ferreira de Melo, o qual afirmou que: "hoje, ao reunirmos, pela terceira vez, tão expressivas autoridades e técnicos das áreas do social, do cultural e do econômico, preocupados com o desenvolvimento educacional, se fortalece uma certeza: a de que o despertamento dos três Estados sulinos para rumos novos, através de uma educação menos impregnada de lirismo e mais preocupada com a produtividade, é realmente um fato." (PARANÁ. Relatório do III Encontro Regional sobre Planejamento da Educação, 1970, p. 9).

Percebe-se novamente, nesse pronunciamento, a ligação que a educação estava tendo com o lado econômico: o importante era a "produtividade", e não a formação em si.

Em fevereiro de 1971, a Secretaria da Educação e Cultura publicou um folheto intitulado Nós, da Educação... onde se afirmava que o Paraná estava se "transformando em celeiro de idéias. Técnicos de outros Estados buscam na nossa experiência subsídios para a composição de um novo sistema educacional". (PARANÁ. Nós, da Educação..., 1971, p. 5).

Afirmava-se também que:

As crianças que entram agora nas escolas chegam em casa contando coisas diferentes. Certos pais ainda não compreendem bem o que está havendo. Elas dizem que não haverá mais exame de admissão e não se falará mais em ensino primário ou ginásio. [...] A criança aprende segundo sua evolução normal. É uma escola que abandona os antigos padrões, e aplica os modernos princípios didáticopedagógicos. Esta escola já funciona em regime experimental no 
Paraná em diversos estabelecimentos de ensino. Em pouco tempo, dominará todas as escolas. ". (PARANÁ. Nós, da Educação..., 1971, p. 7).

Para a implantação dà Lei 5692/71 em Curitiba, foi inclusive elaborado um projeto especial para tal fim. Para tanto foi organizado um "Grupo Especial de Trabalho para a Reforma de Ensino em Curitiba" (GETREC). As razões seriam as seguintes: Curitiba estaria recebendo um grande número de migrantes de outras regiões do Estado, o que tornava a demanda em crescimento superior à capacidade de atendimento; o ensino primário estaria passando por uma expansão muito rápida nos últimos anos; a dificuldade na organização e articulação dos meios de oferta educacionais devido ao crescimento rápido da população e a heterogeneidade da estrutura de ensino, derivada do surgimento de inúmeras variantes ao sistema instituído. (PARANÁ. Documentobase..., 1971).

O GETREC foi instituído pela Resolução n 3872 , de 30 de setembro de 1971, da Secretaria da Educação e Cultura. A data chama a atenção, pois a Lei 5692 foi publicada em julho de 1971 e em setembro, apenas dois meses depois, o plano para a implantação da reforma em Curitiba já estava pronto.

Participando do GETREC, estariam representantes da Secretaria da Educação, Prefeitura Municipal e Sindicato dos Estabelecimentos de Ensino Primário e Secundário no Estado do Paraná. O GETREC selecionou três "metas emergentes" que deveriam ser cumpridas, que eram a conscientização dos professores no que se refere à reforma do ensino, o levantamento da rede escolar e a avaliação das experiências pedagógicas que já haviam sido realizadas em Curitiba.

Em 1973 também foi realizado um balanço da implantação da reforma educacional no Paraná, através do II 
SENPAR (Simpósio de Ensino do Paraná). Nesse mesmo ano, o Paraná conseguiu recursos externos para a execução das metas para a reforma, através de um convênio entre o governo do Estado, por intermédio da Secretaria de Educação e Cultura, e o Acordo MEC/USAID.

Esse foi o segundo acordo desse tipo firmado entre o governo brasileiro e o americano, por intermédio de sua Agência para o Desenvolvimento (USAID). Esse acordo visava à obtenção de um empréstimo destinado à execução de um Programa de Expansão e Melhoria do Ensino e o Paraná foi selecionado entre os Estados brasileiros e contemplado com um financiamento específico para a sua reforma. Acredita-se que isso foi possível devido ao adiantamento do Estado em relação à implantação da reforma.

Em agosto de 1973, tomou posse novamente na Secretaria da Educação e Cultura o deputado Cândido Manuel Martins de Oliveira. No seu discurso, encontram-se as seguintes afirmações:

[...] nunca, na História brasileira, tão decisivo foi o esforço no setor educacional. Com maior ênfase, talvez, o mesmo se pode afirmar a respeito do Paraná. [...] Do êxito que tivermos na batalha do ensino dependerá o futuro de todo o Estado. [...] Em 1969, através da realização do ISENPAR - promovemos uma tomada de consciência coletiva da problemática e das implicações da reforma educacional. Isso antes que o governo federal firmasse, por lei, as diretrizes da reforma, em nível nacional. E constatou-se que os dispositivos promulgados vieram coincidir nitidamente com as conclusões do conclave educacional que o Paraná realizará em caráter pioneiro. Figuramos, portanto, na vanguarda da idealização e concepção dos critérios da reforma. Impõe-se, agora, que logremos nos situar em posição de destaque no que diz respeito à etapa de implantação [...]. (PARANÁ. A estratégia da educação e da cultura, 1973, p. 7). 
Esse discurso resume bem a posição do Paraná em relação à reforma: o Estado foi o pioneiro na sua concepção e queria continuar sendo o pioneiro na sua implantação.

\section{O currículo de Estudos Sociais de 1976}

Em 1976, foi publicado o currículo de Estudos Sociais do Estado do Paraná. Porém logo após a Lei 5692/71 já havia, em nível nacional, o Projeto Reformulação de Currículos do Ensino Fundamental, que propunha para o triênio 1972/1974 a elaboração de currículos para o ensino fundamental pelos Estados e Distrito Federal; a definição de mecanismos de implantação, controle e avaliação; o treinamento de professores para o conhecimento das bases do novo currículo e a preparação de material didático adequado a sua implementação.

O Documento-base para o planejamento prévio para a implantação do sistema de ensino do $1^{\circ}$ e $2^{\circ}$ graus trazia um cronograma de execução para a reforma dos currículos no Paraná.

Porém o novo currículo de Estudos Sociais, elaborado após as reformas de ensino da década de setenta, só foi publicado em 1976 pela Secretaria da Educação e Cultura e começou a ser implantado nas escolas apenas em 1978. Essa implantação foi gradativa. Em 1978, seria a $5^{a}$ série, em 1979, a 6a em 1980, a $7^{\text {a }}$ e em 1981, a $8^{\text {a }}$ série.

Quanto aos pressupostos teóricos, nota-se que nesse currículo existe uma classificação dos conteúdos em três áreas do conhecimento: Estudos Sociais, Comunicação e Expressão e Iniciação às Ciências, como determinava o Parecer 853/71. Já foi visto anteriormente que a disciplina História estava diluída na área de Estudos Sociais juntamente com outras disciplinas, como Geografia, EMC e OSPB. 
Dentro dos objetivos do domínio afetivo estão "adotar atitudes que revelem formação humanística e preparo para a obediência à lei, a fidelidade ao trabalho e integração consciente ao meio social". (PARANÁ. Currículo, 1976, p. 23). Portanto a noção de cidadão que o currículo passa é daquele cidadão pacífico, obediente, ou seja, que não deve nunca contestar a ordem social vigente, apenas aceitá-la.

A questão da evolução e progresso está presente num dos objetivos do domínio afetivo que diz o seguinte: "adquirir valores condizentes à vivência e integração com a realidade histórica e física, através do respeito às tradições, ao patrimônio histórico e da própria participação consciente na obra da evolução da humanidade." (PARANÁ. Currículo, 1976, p. 23). Portanto, o que está fundamentando a visão de História do currículo é a idéia do progresso humano, da evolução linear. Quanto aos conteúdos, percebe-se que dentro dessa evolução são enfatizados os quatro períodos históricos: Idade Antiga, Medieval, Moderna e Contemporânea.

Observa-se também que, nesse currículo, deu-se nova ordenação aos conteúdos da $5^{\mathrm{a}}$ à $8^{\mathrm{a}}$ série. Por exemplo, o conteúdo da $5^{\mathrm{a}}$ série começa com História Antiga e não História do Brasil, como era feito anteriormente.

O que nos parece é que, embora existisse uma equipe encarregada de elaborar o novo currículo de Estudos Sociais, não foram feitas maiores discussões sobre essa elaboração, nem muito menos consultas aos professores em busca de propostas ou opiniões.

A partir do final da década de setenta, começou a haver um crescimento das associações de historiadores e geógrafos, as quais começaram a lutar pelo fim dos Estudos Sociais e pela volta da História e da Geografia como disciplinas autônomas. Na década de oitenta, com a redemocratização do país, passou 
a ocorrer uma redefinição dos conhecimentos escolares através da elaboração de novas propostas curriculares. Havia nessa época uma grande influência das novas tendências historiográficas, as quais voltavam-se para novas problemáticas ligadas à história social, cultural e do cotidiano.

A influência dos novos estudos sobre o processo de ensino e aprendizagem também foi marcante nesse período. Os alunos passaram a ser vistos como participantes do processo de construção do conhecimento, e não mais como meros espectadores.

Conseqüentemente, voltou-se a dar ênfase ao aluno como sujeito participante da História, e a sua realidade passou a ser considerada importante dentro do ensino de História. Os métodos tradicionais de ensino, como a memorização - bastante presente no ensino de História da década anterior - passaram a ser combatidos. Os livros didáticos passaram a ser criticados e iniciou-se um processo de grandes mudanças nos objetivos, conteúdos e métodos de ensino. Essas mudanças, na verdade, ainda estão em processo de elaboração.

A partir da década de oitenta, começou a haver uma maior preocupação com a aproximação entre a História ensinada nas escolas e aquela produzida nas Universidades. Novos temas e novas abordagens tornaram-se cada vez mais presentes. Por outro lado, começou a surgir a consciência de que a História é uma construção e depende da visão de cada historiador. Passou-se a reconhecer que, na verdade, existem várias realidades históricas, as quais foram durante muito tempo deixadas de lado pelos historiadores.

Nesse período também ocorreram amplos debates para a reformulação dos currículos nos Estados brasileiros. Em São Paulo, apenas em 1992 um novo currículo veio a público. No Paraná a nova proposta curricular ficou pronta em 1990, porém desde o início da década de oitenta vinham sendo discutidas 
formas de luta contra os Estudos Sociais, a fim de que a disciplina História voltasse a ser ensinada de forma autônoma. A APAH, Associação Paranaense de História, fundada no final da década de setenta, teve como uma de suas grandes lutas essa questão. Em nível nacional havia a ANPUH, Associação Nacional dos Professores Universitários de História, que também lutou pelo fim dos Estudos Sociais.

Em 1983, no Paraná, a APAH promoveu o I Encontro Paranaense de História e Educação, que tinha como um dos objetivos a volta da História e da Geografia como disciplinas independentes. Após esse encontro foi redigido e divulgado um documento que foi enviado à Secretaria da Educação. Seguem abaixo os trechos mais importantes desse documento.

Diante da gravidade em que se encontra o processo educacional brasileiro, as entidades signatárias do presente documento firmam posição, visando a salvaguarda da área humanística no âmbito do Ensino do $1^{\circ} \mathrm{e} 2^{\circ}$ graus.

Um balanço feito após doze anos de implantação da Lei 5692/71, que fixou Diretrizes e Bases para o ensino de $1^{\circ} \mathrm{e} 2^{\circ}$ graus, revela realidades indiscutíveis: a deformação do ensino em geral; a desqualificação dos cursos profissionalizantes; a saturação do mercado de trabalho; a "panacéia" da licenciatura curta; a dissolução ensino-pesquisa; a não-integração escola-comunidade e a crescente privatização do ensino em todos os níveis. [...]

A imposição dos Estudos Sociais resultou na prática em absoluto e comprovado insucesso. Estudos Sociais, como tal, não cabe em qualquer definição de ciência, não podendo, portanto, ser tratado como disciplina com definição própria. Na verdade, essa pretensa área substituiu disciplinas específicas e consagradas como área de conhecimento, pois sua implantação não se processou em função do conteúdo próprio, mas sim repartindo sua carga horária em parte História, parte Geografia e parte OSPB, na tentativa de ensinar estudos gerais, visando sua integralização. [...] 
A partir das considerações expostas, as entidades comprometidas na luta pela melhoria da qualidade de ensino e reformulação dos sistemas educacionais vigentes, propõem o retorno da História e Geografia. [...] Portanto, entendem os professores, estudantes e entidades abaixo relacionadas que a concretização de uma verdadeira formação humanística deve ter a História, a Geografia, a Sociologia e a Filosofia como instrumentos não só de análise crítica da realidade social, como também de elementos dinâmicos de transformação desta realidade. (Revista da Associação Paranaense de História, 1983, p. 329 a 332).

Esse documento foi assinado pela ANPUH, APAH, professores do Departamento de História da UFPR, professores da prefeitura de Curitiba e outras entidades. Percebe-se então uma participação ativa dos historiadores, aqui representados pela APAH e pela ANPUH Nacional, nessa luta pela volta da História como disciplina nas escolas de $1^{\circ}$ grau.

O Parecer 332/84, do Conselho Estadual de Educação, trata do assunto "Estudos Sociais e seu desmembramento no ensino do $1^{\circ}$ grau" e afirma que existia um embasamento legal para que os Estudos Sociais fossem tratados como matéria de ensino por disciplina, porém desde que se "respeitasse o princípio de integração que fundamenta o currículo." (PARANÁ. Parecer n 332/84, 1984, p. 9). Portanto a matéria Estudos Sociais não desapareceria, apenas se poderia trabalhar com a História e a Geografia em separado, porém "mantendo uma programação resultante da integração dos conteúdos".

O primeiro documento oficial que saiu no Brasil após a Lei 5692 permitindo que se trabalhasse com a História e a Geografia enquanto disciplinas autônomas foi a Resolução n ${ }^{\circ}$ 06 de 1986, do Conselho Federal de Educação. Por essa Resolução, as matérias a serem desenvolvidas da $5^{\mathrm{a}}$ à $8^{\mathrm{a}}$ série seriam Português, Matemática, Ciências, Língua Estrangeira 
Moderna, História, Geografia e OSPB, tratadas como áreas de estudo ou disciplinas.

\section{Conclusão}

A pesquisa que foi realizada permite perceber que o ensino de Estudos Sociais no Paraná, nos anos setenta, acabou provocando uma descaracterização das disciplinas de História e Geografia. Na verdade houve uma falta de discussões sobre os conteúdos que deveriam ser vistos em Estudos Sociais por parte do governo do Estado do Paraná, o qual implantou a reforma de ensino de maneira bastante rápida, buscando manter-se na vanguarda em relação ao restante do país.

O currículo de Estudos Sociais do Estado do Paraná demorou a ser publicado e a única orientação que os professores recebiam até então eram os cursos do CETEPAR, os quais trabalhavam mais com questões referentes às legislações de ensino do período e com técnicas de ensino e não com o conteúdo propriamente dito.

Quando o currículo foi publicado, em 1976, não houve um conteúdo próprio de Estudos Sociais, mas sim uma divisão de conteúdos de História e Geografia. Portanto a interligação entre as disciplinas não ocorreu, ao contrário, elas eram trabalhadas de forma estanque.

Isso tudo nos leva a pensar que se o Estado pretendia que se trabalhassem os conteúdos de Estudos Sociais de forma integrada, então a reforma do ensino não ocorreu da forma como os idealizadores pretenderam. Porém se o objetivo era justamente provocar uma diluição e uma descaracterização das disciplinas na área de Humanas e um ensino de História isento de qualquer análise crítica, então a reforma conseguiu o que pretendia. 
Toda essa situação não impediu, porém, o surgimento de espaços para a criação de novas propostas de ensino dentro das salas de aula. A partir do final dos anos setenta, teve início toda uma contestação aos Estudos Sociais e à maneira como a reforma educacional havia encaminhado as questões referentes ao ensino. Essa contestação ocorreu não só no Paraná, mas no Brasil como um todo e surgiu entre os próprios professores, os quais lutaram para que as disciplinas de História e Geografia voltassem a ser trabalhadas de forma autônoma, num movimento que atingiu as Universidades e as associações de professores que congregam historiadores, como a APAH e a ANPUH.

Em meados dos anos oitenta, essas conquistas foram alcançadas e teve início todo um processo de reformulação curricular. No Paraná, o novo currículo de História foi publicado em 1990 e trouxe como proposta uma renovação no ensino da disciplina.

\section{Referências Bibliográficas}

ALMEIDA, Mariana Josefa de Carvalho. O ensino de História nas escolas estaduais de $2^{\circ}$ grau em Londrina (1971-1982). Curitiba, 1993. Dissertação (Mestrado em História do Brasil) - Setor de Ciências Humanas, Letras e Artes, Universidade Federal do Paraná. 1993.

BOYNARD, Aluizio Peixoto. A reforma do ensino. Lei n. 5692 de 11 de agosto de 1971, publicada no Diário Oficial da União em 12 de agosto de 1971. Rio de Janeiro: Lisa, 1972.

IPARDES. O Paraná reinventado: Política e governo. Curitiba, 1989.

PARANÁ. Conselho Estadual de Educação. Regimento do Conselho Estadual de Educação. Decreto n. 17447 de 19 de março de 1965. Governo do Estado do Paraná. N. 2, 1965. 
PARANÁ. Conselho Estadual de Educação. Sistema Estadual de Ensino. Lei n. 4978, de 05 de dezembro de 1964 e índice remissivo. Governo do Estado do Paraná. N. 1, 1965.

PARANÁ. Secretaria da Educação e Cultura. Currículo. Estudos Sociais $-5^{\text {a a }} 8^{\text {a }}$ série. 1976.

PARANÁ. Secretaria de Estado da Educação. Currículo Básico da Escola Pública do Paraná. Curitiba, 1990.

PARANÁ. Secretaria da Educação e Cultura. Documento-base para o planejamento prévio para implantação do sistema de ensino de $1^{\circ}$ e $2^{\circ}$ graus. Curitiba, 1971.v. 1 e 2.

PARANÁ. Secretaria da Educação e Cultura. A estratégia da educação e da cultura. Discurso de posse do deputado Cândido Manuel Martins de Oliveira. Curitiba, agosto de 1973.

PARANÁ. Secretaria da Educação e Cultura. Centro de Treinamento do Magistério do Estado do Paraná-CETEPAR. Parecer n. 853 de 1971 do Conselho Federal de Educação, Câmara de Ensino de $1^{\circ} \mathrm{e} 2^{\circ}$ graus. Estado do Paraná: Imprensa Oficial, 1971.

PARANÁ. Secretaria da Educação e Cultura. Fundação Educacional do Estado do Paraná. Ministério da Educação e Cultura. Departamento de Ensino Fundamental. Ensino de $1^{\circ}$ e $2^{\circ}$ graus. Estado do Paraná, 1971.

PARANÁ. Secretaria da Educação e Cultura. Discursos proferidos na Sessão Solene de Abertura do I SENPAR - Simpósio de Ensino do Paraná - pelos exmos. Senhores governador Paulo Pimentel e Secretário Cândido Manuel Martins de Oliveira. Curitiba, dez. 1969.

PARANÁ. Secretaria da Educaçãoe Cultura. Nós, da educação... Curitiba, 1971.

PARANÁ. Secretaria da Educação e Cultura. Plano Estadual de Educação do Estado do Paraná. 1973-1976. Curitiba, 1972.

PARANÁ. Secretaria da Educação e Cultura. Fundação Educacional do Estado do Paraná - FUNDEPAR. Coletânea da Legislação Estadual de Ensino: 1969 a 1975. Curitiba, [197-.].

PARANÁ. Secretaria da Educação e Cultura. I ISENPAR - Seminário de Ensino do Paraná. Recomendações finais. Curitiba, 1969.

PARANÁ. SUDESUL / ERPLED. Relatório do III encontro regional sobre planejamento da educação. Curitiba, 1970. 


\section{ABSTRACT:}

This article presents some of the results of the research accomplished on the History teaching in Paraná, in the seventy years. KEY WORDS:

History teaching, teaching reforms, educational legislation. 